\title{
Where are they now? - A Review of the Trinidad \& Tobago Olympic Committee Sports Administrator Courses
}

\author{
By Sherlan Cabralis* \\ Cornell Foo ${ }^{\dagger}$ \\ George Schaefert
}

\begin{abstract}
After 17 years of offering the Sports Administrator Training Programme, a study was conducted to evaluate the Trinidad \& Tobago Olympic Committee (TTOC) programme and examine the graduates' whereabouts to determine if the courses are deemed relevant. A modified instrument, which Taks and Salien (2007) used to examine employment and the effectiveness of sport specific curricula in Canada, was utilized and emailed to the graduates. The results showed that several graduates held strategic positions in various sporting organizations after graduating from the programme. The respondents indicated that communication, both oral and written, and managing finances, including budgeting, were the most important skills. Respondents also indicated that strategic planning and managing finance \& budgeting were the courses that contributed most to their current position. The study reinforces the need to consistently investigate graduates' whereabouts to inform program managers on relevant content and guide other students on the available opportunities.
\end{abstract}

Keywords: Communication, International Olympic Committee (IOC), Trinidad \& Tobago Olympic Committee (TTOC), training programme, tracking students.

\section{Introduction}

Sport has become one of the fastest growing industries in developed countries (Li, Hofacre, \& Mahony, 2001; Pitts \& Stotlar, 2002; Westerbeek \& Smith, 2003). According to Taks (2003) the economic growth of the sports sector has been accompanied by increasing job and career opportunities, which now appear to be endless. In Trinidad \& Tobago, the sport industry consists of different segments, including sport tourism, sporting goods, sport apparel, amateur participant sport, semi-professional sports, recreation, primary and secondary school and university athletics, outdoor sports, and other related sport businesses such as sports management, event management companies, and sport governing bodies.

Although there are several opportunities in the sports industry in Trinidad \& Tobago, there has been limited research on the sport sector as it relates to educational programmes or employment opportunities. It is important for educational institutions to have a clear understanding of the various labour markets, and eventually 'fine-tune' the contents of the academic curriculum to the skills demanded by employers (Taks, et. al 2003). Likewise, it is also

\footnotetext{
* Lecturer, Department of Management Studies, The University of the West Indies, St. Augustine Campus, USA.

${ }^{\dagger}$ Assistant Professor, Department of Kinesiology, Auburn University at Montgomery, USA

${ }^{*}$ Department Head, Department of Kinesiology, Auburn University at Montgomery, USA.
} 
important for various types of training or development programmes to ensure that the courses offered are fulfilling the skills required of the specific industry. This study aims to evaluate the TTOC Sports administrator programme and examine the graduates' whereabouts after completion to determine if the TTOC courses are deemed relevant.

\section{Trinidad \& Tobago (TT) Job Market in Sport}

In some countries, sport employment is still not even considered and recorded as a component of the official job market (Madella, 2003). According to the NTA, in 2014, GDP estimates for non-petroleum sector were 60.9 percent, with the services sub-sector displaying the best performance, at approximately 3.0 percent growth. The TT sport industry is found within the services sector, specifically the personal services group, which had the strongest growth within the services sector at approximately 11.0 percent (NTA, 2015).

In a 2015 study the Research and Planning Department of the Trinidad \& Tobago National Training Agency (NTA), examined the current nature and scope of demand side factors affecting the labour market conditions of the Sporting Industry within Trinidad and Tobago. Volunteerism was considered a plague, which has resulted in many positions being staffed by persons who are passionate about the sport, but are ill equipped technically and academically to achieve the desired success (NTA 2015). According to Madella (2003), the importance of voluntary work is a factor that clearly does not facilitate the analysis of the sector from an employment perspective. Although volunteerism is considered a plague, it makes up a signification portion of the sports labour market. Additionally, respondents were of the view that there are insufficient local bodies providing training for lower level jobs within the Sport industry (NTA, 2015). However, most National Sports Organizations regard the TTOC as an invaluable asset in ensuring their personnel are trained at international levels.

\section{TTOC Sports Administrator Programme:}

The Sport Administration programme seeks to enhance knowledge of the Olympic Movement, its values, the issues facing sport, and the management of sport. It also seeks to develop the capabilities, tools, and practices needed for sport to thrive in the 21 st century, thus helping all our member organisations to professionalise their administrative capabilities (Rogge, 2010). Over the past 17 years, the TTOC has been facilitating continuing education courses for local Sports Administrators to ensure they are meeting the needs of the Trinidad and Tobago sports fraternity (A. Knott, personal communication, October 5, 2017). One of the major objectives is to cover the most common needs and skills of volunteer administrators or elected executives of a sport organization (IOC, 2010). As a result, through the TTOC's Development Certificate Program, 13 sport specific topics were developed. These include: Role \& Structure of the IOC, Communication, Ethics in Sport \& Fair play, Constitution, Financial 
Management \& Budgeting, Public Relations, Event Management, Sport Medicine, Strategic Planning, Marketing, Sponsorship, Development Pathway, and Governance in Sport. These courses are offered over a four-week period at least four (4) times per year, with an average of 25 participants. To date, over 700 sports administrators have completed the program.

Since the programme's inception, neither the curricula nor participants that have taken the course have been assessed or evaluated for effectiveness. The TTOC program is very important for the development of sports administrators. The programme is structured to reach adult students who may or may not have formal educational certification or hold a position in a National Sporting Organization (NSO) or local sports club. According to Williams and Scherzer (2003), the topic/course variability present in any certificate course requires regular evaluations and assessments. Likewise, it is important for TTOC to review the effectiveness of their Sports Administrator courses to ensure that objectives are being met.

The purpose of this study is to provide insight into the graduates' whereabouts after they completed the TTOC Sports Administrator Certificate Program from the years 2005 to 2016 . Specifically, this study explored: (1) why the respondents obtained their current position in sports; (2) the areas of knowledge important to their development as sport administrators; (3) the subject areas relevant for their current position in sports; (4) which particular skills are needed in their current sports position; (5) what courses offered through the TTOC programme contributed most to their current position; (6) the channels used to search for sports related positions; (7) the obstacles in finding a sports related position; and (8) where graduates are currently working. This study should be considered a first step in the analysis of the sport labour market in Trinidad \& Tobago.

\section{Literature Review}

All responsible professions need to periodically monitor their growth and success at placing graduates (William 2003). This premise has led to several research projects tracking students' educational and vocational history. In a prior study by Waite and Pettit (1993), they assessed doctoral graduates from kinesiology departments to determine the adequacy of their own training in providing applied services. This study noted that almost all graduates are spending their time in a variety of work activities. Andersen, Williams, Aldridge and Taylor (1997) contributed to this when they tracked the educational and vocational histories of master's and doctoral graduates who received degrees from 1989 to 1994 with some type of specialization in sport psychology (SP). The primary objective of this study was to provide clear data about career histories of graduates in the field in order to offer prospective students accurate information about future opportunities in SP (Anderson et al. 1997). Master graduates indicated that there were difficulties finding SP work, whereas doctoral graduates secured academic/research positions, indicating that academia was the primary source of employment of sports psychologists with doctoral degrees. In another study, 
Williams \& Scherzer (2003), examined Sports Psychology (SP) graduates between the period 1994 to 1999 , and found that graduates perceived more fulfillment of initial career goals, greater satisfaction with SP work, less frustration over SP career progress, greater ease in finding paid SP consulting work, and more confidence in fulfilling future career goals. The findings provide some guidance for current and prospective students regarding graduate training and career opportunities.

Waite and Pettit (1993), Anderson et al. 1997 and Williams \& Scherzer (2003) all utilized the same questionnaire, which was mailed or emailed to their participants. The questionnaire asked for demographic and educational information, past and current positions, time worked as well as income, initial and future career goals, fulfillment of career goals, level of difficulty finding paid and unpaid work, satisfaction with work, causes of frustration in one's career, confidence in fulfilling future goals, and open-ended questions such as "what advice would you have for someone who is interested in beginning study in sport/ exercise psychology?" (Williams \& Scherzer 2003). Like previous studies, Meyers, Coleman, Whelan, \& Mehlenbeck (2001) also examined careers in sport psychology. Their findings suggested that there are viable career options in this field, both in academics, predominantly for sport scientists, and applied settings, for largely clinical and counselling psychologists (Meyers et al., 2001).

Taks, Delheye, Hartmann-Tews, \& Demuynck, (2003) tracked the careers of graduates in sport and sport-related programs in several European countries. In their study, they summarized the methodology and response rates of other research done between the period 1994-1998 in Germany, France, Italy, UK and Flanders (Belgium). That study had a response rate that ranged from 17-64 percent. Taks et. al. (2003) continued the same line of inquiry consisting of five major sections: personal data, education curriculum, career curriculum, specifications about current job and future employment aspirations. Results of the study reported that commitment, communication skills (oral), working in a team, handling pupils/children and self-management were the skills considered most important by those graduates in physical education, sport and recreation.

Taks and Salien (2003) conducted another study to analyze the employment status of graduates from the bachelor and master programs of the Faculty of Human Kinetics at the University of Windsor, Canada. They concluded that the growing sport industry does not seem to attract many of the HK graduates of this program (Taks et al. 2003). Van Schalkwyk, Niyimbanira, and Surujlal (2012), using a qualitative approach, explored the experiences of sport management graduates from graduation to employment through in-depth interviews and concluded that the experience gained through internship and the database of possible employers greatly enhanced the employability of sport management graduates.

Several other studies have been done on university graduates, which include but are not limited to employment status, job mismatch, employability, earnings and unemployment. Specific to Social Sciences graduates, Teichler (1989) reviewed studies on university graduates from various western European countries during the 1980s and noted that in most countries, graduates in the social 
sciences and the humanities face greater than average employment difficulties. Allen (1998), using census data from Canada on unemployment, occupation, and income, showed that university graduates in education, the humanities, and the social sciences are highly employable. However, most of the respondents were in their twenties, so the survey did not indicate the full lifetime trajectories of earnings, but only the experience of people who have recently established themselves in the labour market. Drewes and Giles (2001) used the Survey of Labour and Income Dynamics (SLID) to look at the labour market experiences of graduates of bachelor's level programs. SLID offers rich detail on the labour market experiences of individuals from the beginning of 1997, and its longitudinal design is ideally suited for tracking changes over time. As a group, Humanities and Social Science received lower wages (Drewes and Giles, 2001).

Drewes (2002) compared the labour market experiences between humanities and social science graduates and those who graduated from more applied programs in Canada. The study found that the former may initially be disadvantaged by the lack of vocational content in their studies, but once established in the market, they do as well as graduates from applied fields of study. Ama (2008) used a case study and found that a great majority $(72.5 \%)$ of social sciences graduates (from the University of Botswana) hold jobs matching their level and field of education. Likewise, Purcell and Elias (2006) found that social science PhD-holders are more likely than those with doctorates in other broad discipline areas to remain in academia and that social science PhDs in UK are satisfied with the type of job they are doing, as well as the job's relevance to their training.

Ballarino and Bratti (2009) used the Italian National Statistical Institute (ISTAT) Graduates' Employment Survey (GES) to understand the evolution of graduates' employability by degree subject over time in Italy. They found that the degrees ensuring the best employment outcomes are those in technical, hard sciences, and hard social sciences (economics, statistics) fields. Their paper was the first one to attempt a comparison across time using data on graduates for a decade with a primary focus on field of study. Buonanno and Pozzoli (2009), utilizing the ISTAT GES, also revealed that 'quantitative' fields (sciences, engineering, and economics) ease the transition into the first job and increase employment probability and early earnings, conditional on employment, whereas graduates in the humanities and social sciences are the most disadvantaged in terms of early labour market outcomes. Kalamatianou and Kougioumoutzaki (2012) examined two important labour market outcomes of social sciences graduates, employment status and job-studies relevance, taking into account gender and time of graduation. Using a case study on graduates of a public University that exclusively serves social sciences, they noted that research results concerning the employment prospects of social science graduates are not consistent. Results indicate deterioration of the graduates' employment opportunities, lower employment status of female graduates, and persistence of a high degree of 'job-studies no relevance' over time (Kalamatianou and Kougioumoutzaki, 2012)

Most studies on university graduates' employment status used national labour force surveys, questionnaires and interviews. However, these studies only 
addressed graduates from universities. These studies did not include smaller training programs, which are conducted by several International Sports Federations and volunteer institutions. Notably, many sports administrators in Trinidad \& Tobago are not university graduates, which the NTA (2015) study indicated as a key issue because of the lack of management skills within the industry. Despite cadres of Sports Management (SM) graduates being produced by UWI and UTT, the industry still lacks management personnel (NTA 2015) since many SM graduates are not employed in the National Sports Organizations.

The current study was designed to build on the previous work by examining a smaller training program that attracts students who may or may not have a sports related degree and may provide some guidance for current and prospective students regarding graduate training and career opportunities.

\section{Methodology}

The study's participants consisted of graduates (2005-2016) from the TTOC Sports Administrator programme. An online questionnaire was emailed to 450 graduates four times between the period November 2016-April 2017. Of the 450 questionnaires sent out, $11 \%$ bounced back. Less than $10 \%$ responded. A modified instrument was utilized for this study. The instrument was first used in a report by Taks and Salien (2007) that looked at sport and employment in Canada and the effectiveness of sport specific curricula. Their questionnaire assessed sports graduates in terms of the jobs they performed, the organizations they were employed by, the skills required, the reasons why graduates moved out of the sports sector (if applicable), and the reasons for their satisfaction or lack thereof. Personal data and education curriculum information was also collected in addition to their career path, specifications about the current job, and future employment aspirations. This survey was adapted for the TTOC programme, based on input from faculty members and TTOC lecturers, and focused on TTOC education curriculum information, the position they presently hold, the organizations they are employed by, and the skills required for their position, as well as personal data.

Specifically, the questionnaire was adapted to examine whether the graduates are directly involved in the sporting industry and if the taught courses and skills developed in the programme were relevant to their positions. As a result, the questions were divided into two categories (1) questions on TTOC education curriculum and (2) questions on skills required, skills needed, position held and personal data (see appendices).

\section{Analysis Approach}

The data collected from the student surveys were coded and entered into the Statistical Package for Social Sciences (SPSS). The data were then analysed by performing a Descriptive Analysis. The open-ended questions on the survey were analysed using Content Analysis. 


\section{Research Findings}

\section{Demographics of Respondents}

Table 1 provides a breakdown of the age group. There was less than a $10 \%$ response rate with a distribution of $69 \%$ female and $39 \%$ male respondents. With regards to age, $32 \%$ were over 50 and $27 \%$ were under 30 . The average age of the respondents was 44 years. In addition to completing the TTOC programme, $50 \%$ indicated that they had a BSc is various concentrations such as Sociology, Project Management, Business Management etc. Another 14\% indicated that they had a MSc degree in Sports Management or Human Recourse Management or Sports Policy, Management and International Development. Overall, $16 \%$ of the respondents had a sports related degree.

Table 1. Respondents Age Group

\begin{tabular}{|l|c|}
\hline Age Group & \\
\hline Under 30 & $27 \%$ \\
\hline $31-40$ & $18 \%$ \\
\hline $41-50$ & $23 \%$ \\
\hline Over 50 & $32 \%$ \\
\hline Total & $\mathbf{1 0 0 \%}$ \\
\hline
\end{tabular}

Table 2. Responses for Obtaining Current Position in Sports

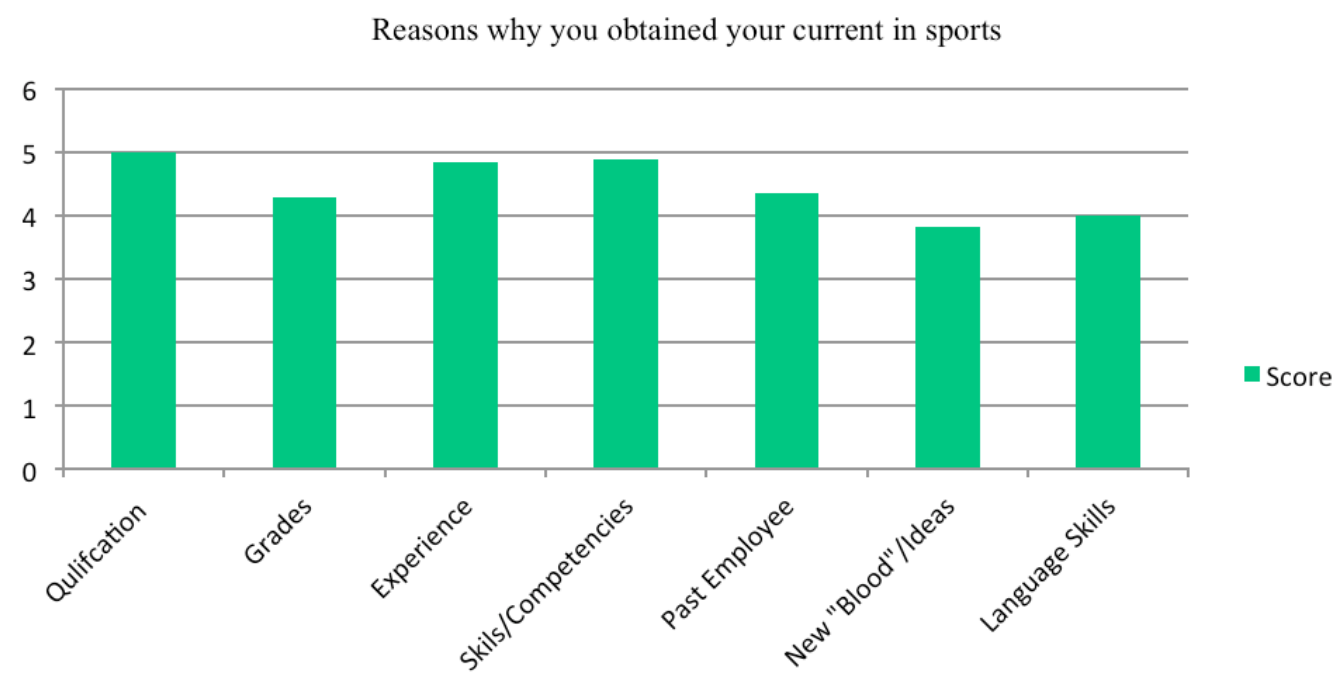

\section{Reasons for Obtaining the Current Position}

Table 2 presents responses for obtaining the current position in sports. Respondents were asked to rank why they believed they obtained their current position in sports. 32 percent of respondents identified that their skills and competencies were the most important reason for obtaining their current position. Secondly, professional experience was regarded as important in obtaining their current position (29\%). The TTOC graduates' grades (59\%) and the organization 
wanting "new blood" or new skills or new ideas (42\%) were regarded as the least important reasons for obtaining their current jobs.

\section{Skills needed in your Current Position}

Respondents were asked to list the three most important skills required for their current position. Six skills were identified by the respondents: communication (written and oral) (50\%), budgeting/finance (23\%), creativity (14\%), marketing (14\%), and managing people (14\%). Other skills reported as important by respondents were decision-making, problem solving, planning, and organizing.

Table 3. Responses to the subject relevant to current position

Subject areas ranked relevant in their current position

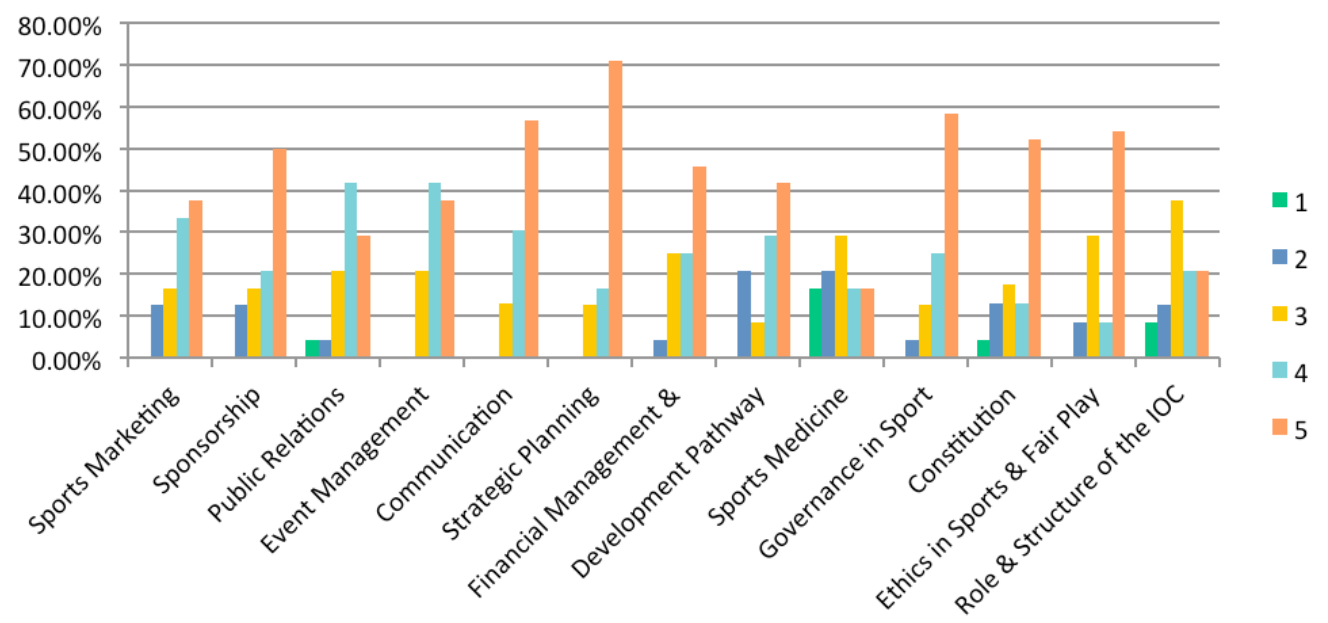

Courses Contributing to Current Position

Table 3 presents the TTOC subjects relevant to the respondents' current position. Respondents were asked to list the courses from the TTOC program that contributed most to their current position. Courses that were listed most frequently included strategic planning (26\%), managing finance \& budgeting (17\%), and governance (17\%). Furthermore, events management (13\%), human resource management (9\%), marketing (9\%) and communication $(9 \%)$ were considered important courses contributing to respondents' current positions. 
Table 4. Responses for the Reasons why the Respondents Obtain their Current Position

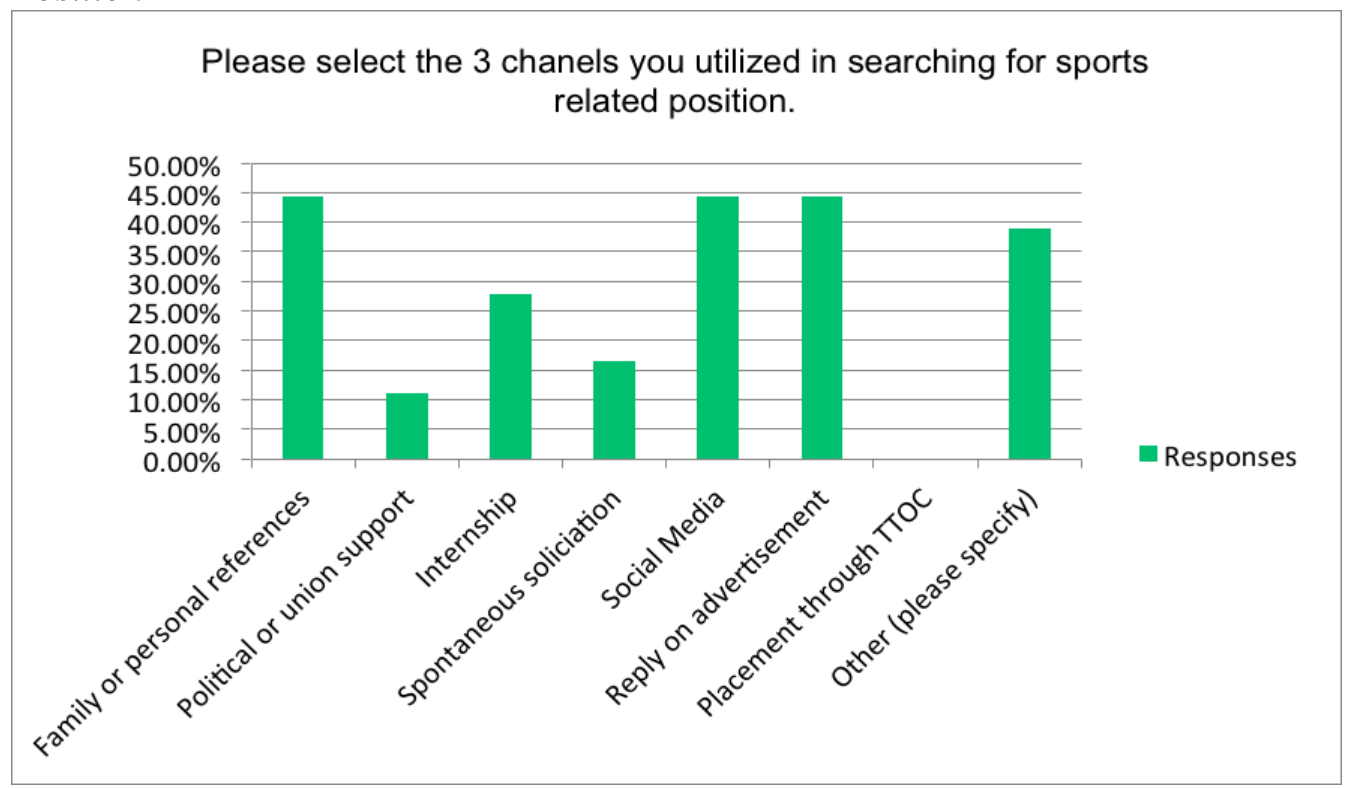

Channels used in searching for your Current Position

Table 4 presents the methods for how the respondents obtained their current position. In searching for a position, $44 \%$ of the respondents indicated family or personal reference, social media, and replying to an advertisement. Furthermore, spontaneous solicitation (17\%), political or union support (11\%) and employment office $(11 \%)$ were also indicated as important channels. Board of education and placement through the TTOC were not an option.

Table 5. Responses for Obstacles in finding a Sports related Position

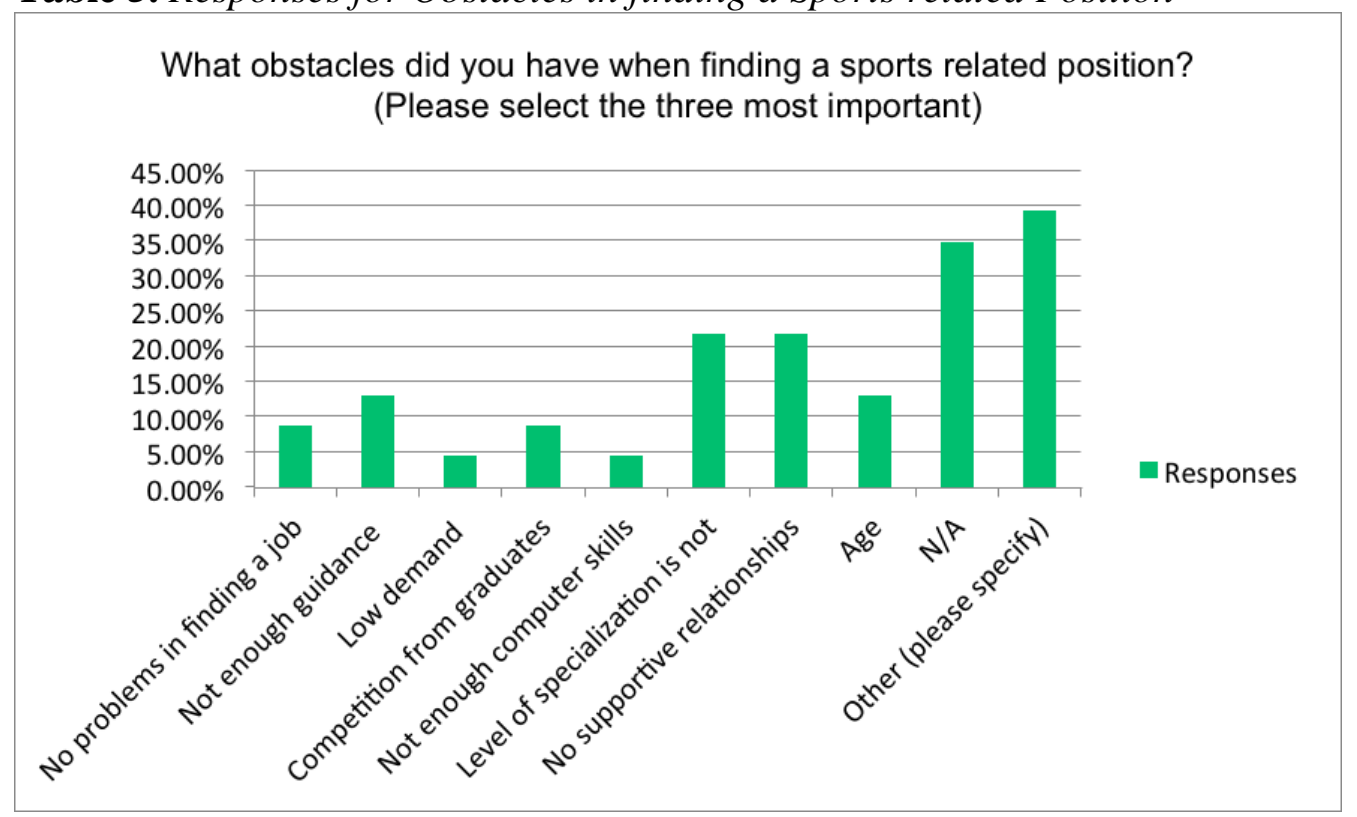




\section{Obstacles Found in searching for your Current Position}

Table 5 presents the obstacles in finding a sports related position. Respondents indicated the most important obstacles to looking for a position including: level of specialization is not high enough (22\%) and no supportive relationships (21\%). 35\% indicated that the choices were not applicable. Some of their other responses were as followed: "not enough experience", "gender", "too many organizations want assistance for free", "most sport related positions were not suitable to sustain financial requirements" and "in Trinidad, SportsRelated positions are highly political, and to some extent, sexist in nature - it is about who you know or who knows you"

\section{Types of Organizations Graduates are Currently Employed}

Since completing the TTOC programme, respondents now serve in the positions of president, board member, chairman, chief administrative officer, program manager, committee member, and other administrative roles. The respondents are directly involved in various National Governing Bodies (26\%) including rugby, swimming, cycling and volleyball. Additionally, some respondents hold positions in their local sports clubs (40\%).

\section{Discussion}

The purpose of this study was to provide insight into the graduates' whereabouts after they completed the TTOC Sports Administrator Certificate Programme from the years 2005 to 2016. A questionnaire was emailed to graduates between 2005 and 2016 to track their career in the Trinidad \& Tobago sports industry. The data presented from this research, and our interpretation of it, has its limitations. The return rates were low, and our sample could be biased by the return rates from those graduates who found positions in a sporting organization.

The results show that the majority of the graduates had other academic degrees or professional certificates before they achieved the TTOC certificate. Moreover, $81 \%$ did not have any sports related degree or certificate. This result confirms that intended students, i.e. the volunteer administrators or elected executives of a sports organization (IOC, 2010), were the core representatives of the student population. These results also confirm the significance of the program and highlight the fact that although the graduates were qualified in other fields, they recognize the need for the TTOC program, as indicated by the NTA (2015) research stating that most National Sports Organizations regard the TTOC as an invaluable asset in ensuring their personnel are trained at international levels.

With regards to the curriculum, students thought that strategic planning, communication, governance in sport, constitution, ethics in sports and sponsorship were very important, with over 50\% significant rating. Graduates also valued 
the relevance of financial management \& budgeting, events management and sports marketing. However, in their current positions, strategic planning, financial management \& budgeting and governance were the most important. On the other hand, the role \& structure of the IOC, sports medicine, development pathways and public relations were considered less relevant in the curriculum and their current position. This result shows that the majority of the courses were relevant to the graduates' position and responsibilities, confirming the strength of TTOC Sports Administrator Programme.

The most important reasons graduates from the TTOC programme gave regarding the obtainment of their current position were skills and competencies and professional experience. This is not surprising given the dominance of training and experience of employment. Furthermore, the skills needed for current positions - such as communication (written and oral), budgeting/ finance, creativity, commitment, marketing, and managing people - were all covered in the courses offered in the programme and directly related to strategic planning and communication. This result agrees with Taks and Salien (2003), who reported that commitment and communication skills (oral) were the skills considered most important by those graduates in physical education, sport and recreation. Additionally, the courses offered also enhanced the graduates' decision-making, problem solving, planning and organizing skills, which were identified as relevant skills.

When searching for a position in the various sport organizations, family or personal reference, social media and replying to an advertisement appeared to be the most utilized channel, whereas the low demand and a limited level of specialization appeared to be the most important obstacles in finding a position. Taks and Salien (2003) also indicated that the most important channels for job search included: family or personal relationships and reply on advertisements, and the most important obstacles reported were the low demand for HK graduates and the low level of specialization. This is significant information, which can be used by programme managers to guide past and current students.

However, studies from Anderson et al. (1997) stated that master graduates indicated that there were difficulties finding SP work and Taks et al. (2003) concluded that the growing sport industry does not seem to attract many of the HK graduates. All TTOC graduates are in a sports related position as indicated in the position they currently hold i.e. president, board member, chairman, chief administrative officer, program manager, committee member and other administrative roles. Many of the graduates are in strategic positions, a result which validates the importance of TTOC Sports Administrator programme.

\section{Conclusion}

Volunteerism was considered a plague (in Trinidad \& Tobago), which has resulted in many sports organizations being staffed by persons who are passionate about sports but ill-equipped technically and academically to achieve desired success (NTA 2015). The IOC Sports Administrator Programme addresses some 
of these inadequacies highlighted by the NTA. Furthermore, the results show that TTOC programme is positioned to achieve the IOC's objective of "professionalizing their (graduates) administrative capabilities". Indeed, if the TTOC wants to cover the most common needs and skills of volunteer administrators or elected executives of a sport organization, there should be improvements made to the affiliation between training programmes and the sport fraternity.

The study did reinforce the need to consistently investigate graduates' whereabouts in order to inform program managers about relevant content and guide other students towards available opportunities. Ultimately, for the Trinidad \& Tobago sports industry to improve technically and academically, more studies are needed to evaluate the graduates being produced by the sports management programmes at TTOC, University of the West Indies, St. Augustine and University of Trinidad \& Tobago. This will allow for better preparation of graduates to take on key positions in today's growing sport industry.

\section{References}

Allen, R., 1998. The Employability of University Graduates in the Humanities, Social Sciences, and Education: Recent Statistical Evidence.

Ama, N.O., 2008. Transition from higher education to employment: A case study of graduates of faculty of social sciences University of Botswana. Educational Research and Reviews, 3(8), p.262.

Andersen, M.B., Aldridge, T., Williams, J.M. and Taylor, J., 1997. Tracking the training and careers of graduates of advanced degree programs in sport psychology, 1989 to 1994. The Sport Psychologist, 11(3), pp.326-344.

Anderson, M. B., \& Williams, J. M. 1997. Tracking the training and careers of graduates of advanced degree programs in sports psychology. Sport Psychologist, $11(3), 326$

Ballarino, G. and Bratti, M., 2009. Field of study and university graduates' early employment outcomes in Italy during 1995-2004. Labour, 23(3), pp.421-457.

Buonanno, P. and Pozzoli, D., 2009. Early labour market returns to college subject. Labour, 23(4), pp.559-588.

Drewes, T. and Giles, P., 2001. Liberal arts degrees and the labour market. Perspectives on Labour and Income, 13(3), p.27

International Olympic Committee 2010. Sport Administration Manual. Roger Jackson \& Associates Ltd: Calgary, Canada

Li, M., Hofacre, S., Mahony, D., 2001. Economics of sport. Fitness Information Technology: Morgantown, WV.

Kalamatianou, A. and Kougioumoutzaki, F., 2012. Employment status and job-studies relevance of social science graduates: The experience from a Greek public University.

Madella, A., 2003. Methods for analysing sports employment in Europe. Managing Leisure, 8(2), pp.56-59.

Meyers, A.W., Coleman, J.K., Whelan, J.P. and Mehlenbeck, R.S., 2001. Examining careers in sport psychology: Who is working and who is making money? Professional Psychology: Research and Practice, 32(1), p.5. 
Pitts, B.G. and Stotlar, D.K., 2007. Fundamentals of sport marketing. Fitness information technology.

Purcell, K. and Elias, P., 2006, The Employment of Social Science PhDs in Academic and non-Academic Jobs: Research Skills and Postgraduate Training, Economic and Social Research Council, UK

Purcell, K., Elias, P., Durbin, S., Davies, R. and Warren, S., 2006. The employment of social science PhDs in academic and non-academic jobs: research skills and postgraduate training. Economic and Social Research Council.

Research, Planning and Development Department, 2015. A Quantitative Research on Labour Market Demands in the Sport Industry, National Training Agency

Taks, M., Delheye, P., Hartmann-Tews, I. and Demuynck, N., 2003. Tracking the careers of graduates in sport and sport-related programmes: a European perspective. Managing leisure, 8(2), pp.97-103.

Taks, M. and Salien, R., 2007. Research report Sport and employment in Canada: An exploratory step. Department of Kinesiology

Van Schalkwyk, P., Niyimbanira, F. and Surujlal, J., 2012. Transition from graduation to employment: a qualitative exploration of Sport Management graduates' experiences: human resource issues in sport. African Journal for Physical Health Education, Recreation and Dance, 18(Supplement 1), pp.214-226.

Waite, B.T. and Pettit, M., 1993. Work experiences of graduates from doctoral programs in sport psychology. Journal of Applied Sport Psychology, 5(2), pp. 234-250.

Westerbeek, H. and Smith, A., 2002. Sport business in the global marketplace. Springer.

Williams, J., 2003. Tracking the training and careers of graduates of advanced degree programs in sport psychology, 1994 to 1999. Journal of Applied Sport Psychology, 15(4), pp.335-353.

Williams, J., 2003. Tracking the training and careers of graduates of advanced degree programs in sport psychology, 1994 to 1999. Journal of Applied Sport Psychology, 15(4), pp.335-353. 


\section{Appendices}

\section{Questions on TTOC education curriculum}

How valuable do you feel the following areas of knowledge are to your development as a sports administrator? (please check scale)

\begin{tabular}{|c|c|c|c|c|c|}
\hline Tick the approach box & $\begin{array}{c}\text { Not at } \\
\text { all }\end{array}$ & A little & Moderate & $\begin{array}{c}\text { Quite a } \\
\text { lot }\end{array}$ & $\begin{array}{r}\text { Great } \\
\text { deal }\end{array}$ \\
\hline $\begin{array}{l}\text { a. Management of Activities } \\
\text { including marketing, } \\
\text { sponsorship, public } \\
\text { relations, event } \\
\text { management, } \\
\text { communications }\end{array}$ & & & & & \\
\hline $\begin{array}{ll}\text { b. } & \text { Management of } \\
\text { Resources including } \\
\text { strategic planning, } \\
\text { financial management \& } \\
\text { budgeting } \\
\end{array}$ & & & & & \\
\hline $\begin{array}{l}\text { c. Developing elite athletes } \\
\text { including development } \\
\text { pathway, sport medicine }\end{array}$ & & & & & \\
\hline 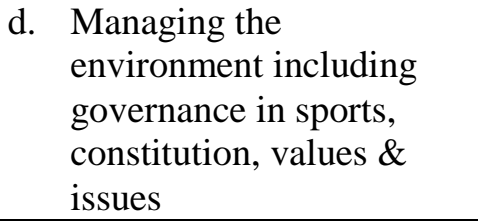 & & & & & \\
\hline
\end{tabular}

Please rate these subject areas as to how relevant they were in your current position in sports? (check the appropriate level; 1 = not at all relevant, $2=$ slightly relevant, $3=$ relevant, $4=$ very relevant and $5=$ extremely relevant)

\begin{tabular}{|l|l|l|l|l|l|l|}
\hline & & \multicolumn{5}{|c|}{ Current position } \\
\hline & & $\mathbf{1}$ & $\mathbf{2}$ & $\mathbf{3}$ & $\mathbf{4}$ & $\mathbf{5}$ \\
\hline Sports Marketing & & & & & & \\
\hline Sponsorship & & & & & & \\
\hline Public Relations & & & & & & \\
\hline Event Management & & & & & & \\
\hline Communications & & & & & & \\
\hline Strategic Planning & & & & & & \\
\hline Financial Management \& Budgeting & & & & & & \\
\hline Development Pathway & & & & & & \\
\hline Sports Medicine & & & & & & \\
\hline Governance in Sport & & & & & & \\
\hline Constitution & & & & & & \\
\hline Ethics in Sports \& Fair play & & & & & & \\
\hline Role \& Structure of the IOC & & & & & \\
\hline
\end{tabular}




\section{Questions on skills required and personal data}

Please indicate why you think you obtained your current position in sports? (Indicate the three most important in order by 1,2,3)

My qualifications were the best/most appropriate

My grades were the best/ most appropriate

My professional experience was the best/ most appropriate

My skills/ competencies were the best

I already worked for the organization, they already knew me, I was a low risk hire The organization wanted 'new blood' / new ideas/ new skills

I knew an influential person in the organization

I have the necessary language skills

Other, (please specify)

What are the 3 most important skills required by your current sports position?

a.

b.

c.

List three courses from the TTOC programme that contributed most to your current position in sport?

a.

b.

c.

Which channels did you use in searching for sports related position? (Indicate the three most important in order by 1,2,3)

Family and/ or personal references and relations

Political and/ or union support

Internship/ voluntary work

Spontaneous solicitation

Reply on advertisement

Placement through TTOC

Other (please specify). 
